\title{
Don Juan Rafael Mora: Empresario por antonomasia del siglo decimonónico
}

Tomás Arias Castroi, Universidad de Costa Rica y Mauricio Ortiz Ortizii, Empresario

Recibido: $16 / 3 / 2015$

Aceptado: 20/05/2015

Desde finales del siglo XVIII, el poblado de San José, también Ilamado Villa Nueva, empezó a experimentar un paulatino crecimiento económico y comercial en diversas áreas y ámbitos, lo cual le significó un ostensible reposicionamiento en el derrotero histórico que venía construyendo desde su antigua fundación en 1736. Proceso que se acrecentó con acelerada magnitud a partir de las primeras décadas del siglo XIX y que convirtió a dicha localidad en punto focal para el inminente desarrollo socioeconómico que Costa Rica estaba a punto de experimentar en los años subsiguientes.

En ese sentido, no fue fortuito que para el momento en que el monarca español Carlos III dispuso en 1766 la creación de una Factoría de Tabacos en nuestro suelo, fuese precisamente la localidad josefina la que albergase dicho ente, provocando con ello la captación regular de una serie de rentas para nuestro incipiente y raquítico erario. También, la entrada en vigencia en 1812 de la afamada Constitución Política de la Monarquía Española (conocida popularmente como Constitución de Cádiz) permitió el establecimiento en San José (1814) del primer centro de educación formal de nuestra historia bajo el nombre de Casa de Enseñanza, con lo que se dio inicio a la primigenia actividad educacional costarricense. Institución que con posterioridad y bajo una égida eclesiástica, modificaría su nombre en 1815 por el de Casa de Enseñanza de Santo Tomás. Asimismo, le correspondió a San José la peculiar circunstancia de producir en su suelo, hacia 1816, el primer cafetal del que se tiene noticia de la mano del presbítero Félix Velarde Umaña, con lo que, literalmente, se sembraron las bases del producto comercial más importante de Costa Rica en el siglo XIX.

i Tomás Arias Castro es profesor de la Facultad de Derecho de la Universidad de Costa Rica coordinador de la cátedra de Historia del Derecho.

Mauricio Ortiz es un empresario, productor e investigador del libro Crónicas Periodísticas de La Campaña Nacional 18551860.
Tomás Federico Arias y Mauricio Ortiz $\mathrm{O}$. Don Juan Rafael Mora: Empresario por antonomasia del siglo decimonónico. Revista Comunicación. Año 36, vol. 24, núm. 1. Enero - julio, 2015. Tecnológico de Costa Rica. ISSN Impreso: 0379-3974/ e-ISNN: $1659-3820$ 
Así las cosas, correspondió entonces a la progresista, visionaria y emprendedora Ciudad de San José (título formal que recibió en 1813), atestiguar el insigne nacimiento del infante Juan Rafael Mora en el hogar conformado por el reconocido comerciante y funcionario público don Camilo Mora Alvarado y por doña Ana Benita Porras Ulloa. Alumbramiento que se verificó el 8 de febrero de 1814 en una casa ubicada en la actual Calle $2^{\mathrm{a}}$ y las Avenidas 0 y $2^{\mathrm{a}}$.

Desde muy temprana edad, los distintos avatares y episodios de índole comercial y económica en los que estuvo profusamente involucrado don Camilo Mora, fueron el escenario idóneo para que el joven Mora fuese entendiendo y asimilando todos los intríngulis propios de dichas actividades, los cuales asimiló con peculiar presteza dado el precoz talento que mostró siempre para ello.

\section{LA ESCUELA PATERNA}

Don Camilo Mora se distinguió desde siempre por la intachable honradez que aplicó tanto en sus negocios privados como en los distintos puestos gubernamentales en los que le correspondió desempeñarse. Situación que provocó que su nombre se asociase a un ejercicio prístino de marcada solvencia moral, logrando establecer gran cantidad de relaciones comerciales en los más variados estratos del país con múltiples personajes de la coyuntura histórica en la que vivió.

Así, entre las variadas actividades a las que Mora Alvarado se dedicó estuvo la comercialización de telas, abarrotes, objetos agrícolas, enceres de uso doméstico, instrumentos para el trabajo rural, alimentos $y$, en general, toda una amplia gama de productos de necesidad ordinaria. De modo paralelo, el otro gran derrotero que desarrolló estuvo ligado a operaciones comerciales con bienes inmuebles, por medio de las cuales realizaba transacciones como compraventas, préstamos, fianzas, comodatos, alquileres, cesiones, hipotecas, usufructos, garantías e incluso la conformación de sociedades pecuniarias con otros individuos dedicados a este tipo de negocios, tal y como la que conformó en 1813 con dos de los ciudadanos más preeminentes de nuestra sociedad: don José Rafael Gallegos Alvarado (futuro segundo Jefe de Estado) y don José Santos Lombardo Alvarado (hermanastro del anterior y uno de los futuros artífices de nuestra independencia).

Pero, lamentablemente, la integridad que Mora Alvarado practicó con reiterado afán, muchas veces no fue repetida por los individuos con los que negociaba, razón por la que en más de una ocasión se vio envuelto en varios litigios judiciales, así como en serias penurias económicas, ocasionadas por las desfachatez moral de aquellos que se aprovechaban de su magnanimidad y confianza. Circunstancias agravadas por la sempiterna buena fe que don Camilo utilizaba al momento de realizar algún tipo de negocio o transacción, pues, ilusamente, creía que sus contrapartes comerciales se comportarían siempre de la misma manera.

Fue entonces cuando, desde la temprana edad de 18 años, el joven Mora le solicitó a don Camilo su aquiescencia para emanciparse de su autoridad paterna. Autonomía la cual se verificó en 1832 y que le permitió a Mora realizar su primera operación comercial propia, cuando le otorgó un poder a don Manuel Zeledón para que procediese al cobro de una deuda en contra de don Jacinto García o, en su defecto, contra su fiador don Ramón Pomerol.

Para 1833 y al igual que su padre lo había hecho en antaño, don Juan R. Mora abrió un establecimiento de comercialización de diversas mercaderías y productos en el pórtico de su casa paterna, el cual rápidamente empezó a producirle constantes réditos. Mismo año en que incursionó en el accionar comercial relacionado con bienes inmuebles, empezando a efectuar toda la amplia gama de operaciones jurídicas que dicha actividad permitía con relación a fincas, sembradíos, parcelas, terrenos, haciendas, domicilios, dehesas y, en general, sobre todo tipo de propiedades.

Tres años más tarde y como consecuencia de la complicación severa de una serie de aflicciones en su salud, don Camilo Mora emitió su testamento en agosto de 1836 en el que reconoció la existencia de varias deudas y deberes pecuniarios. Fue así como, para el momento en que Mora Alvarado murió a los 56 años (septiembre, 1836) su hijo Juan Rafael le obsequió un último momento de tranquilidad ética a su alicaído progenitor, pues le ofreció asumir la totalidad de sus obligaciones pecuniarias, comprometiéndose a pagar y satisfacer cada uno de esos débitos a los acreedores y beneficiarios correspondientes.

\section{LA EXPANSIÓN COMERCIAL}

Después de los resultados positivos que había tenido con su pionero establecimiento de mercaderías, así como con su exitoso accionar en las negociaciones transaccionales de propiedades y terrenos, Mora decidió incursionar en un nuevo campo comercial que 


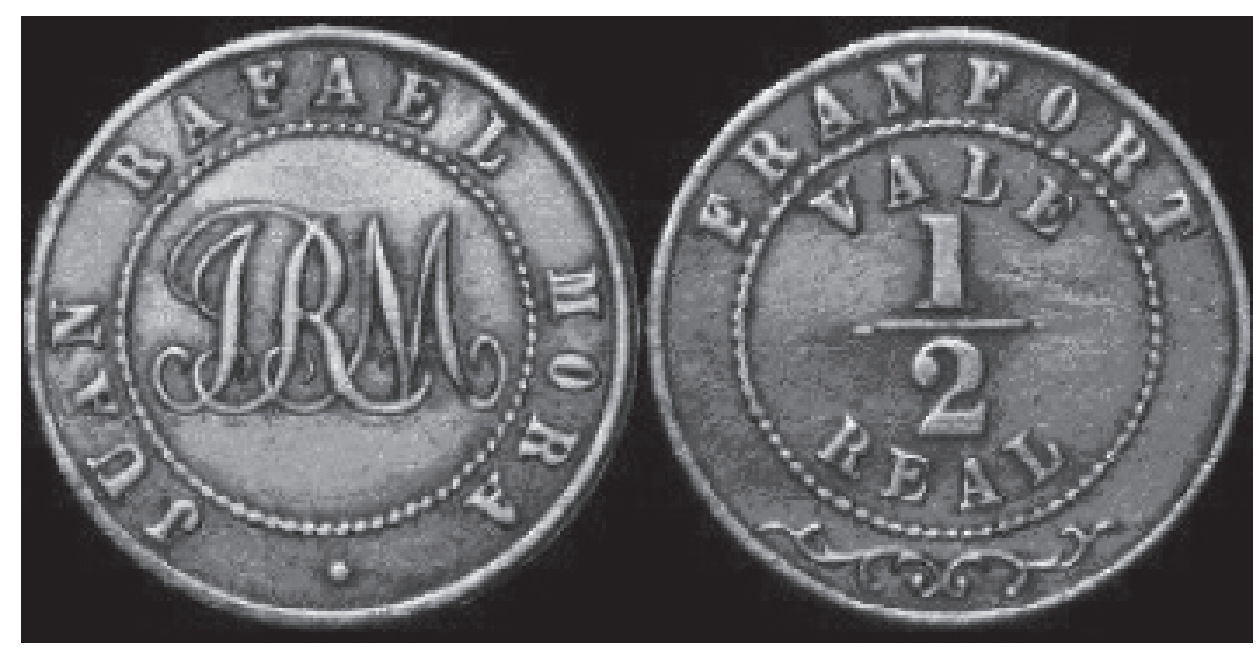

Boleto de café por valor de medio real de la finca Frankfort, perteneciente a don Juan Rafael Mora Porras

estaba por experimentar un inusitado y fortísimo auge: el cultivo de café.

Fue en 1838 cuando don Juan Rafael inició sus primeras operaciones pecuniarias relacionadas a la siembra, recolección y venta de granos de café, tanto en algunos inmuebles de su propiedad, como en asocio con otros productores de dicha semilla. Pero, gracias a su visión empresarial, rápidamente comprendió que dicho negocio no podía estar circunscrito a nuestro territorio.

Las anteriores consideraciones, así como el deseo de expandir sus actividades comerciales fuera de Costa Rica, fueron las razones que llevaron a Mora a emprender, en ese mismo año de 1838, su primer viaje de negocios a la localidad nicaragüense de El Realejo. Un año más tarde con el objetivo de transportar en gran cantidad varias mercaderías y productos, don Juan Rafael presentó un pedimento formal ante las autoridades del Poder Ejecutivo para la concesión de una patente marítima que le permitiese efectuar distintas travesías comerciales con un bergantín que había adquirido recientemente y al que llamó Goleta Cía. Derecho que le fue dado por el egregio gobernante cartaginés Lic. Braulio Carrillo Colina.

Ahora bien, en enero de 1840, Mora hizo un viaje de negocios a la ciudad salvadoreña de Sonsonate, al que le siguió una pionera serie de tres travesías comerciales a la isla de Jamaica, los cuales efectuó de modo sucesivo, en 1840, 1841 y 1842. Periplos caribeños que tuvieron como fin la adquisición de una considerable serie de productos manufacturados y objetos de raigambre británica para su posterior venta en Costa Rica, realizados no solo por medio de la compra directa de dichos enseres, sino por el intercambio y negociación que hacía con sus sacos de café.

Durante ese mismo año de 1842 y dado el enorme crecimiento que el comercio del café tuvo a partir de esa coyuntura en Costa Rica, Mora Porras viajó a uno de los principales mercados suramericanos de comercialización de dicho grano: Chile. Nación en la que, asimismo, pudo empezar a negociar y enviar gran cantidad de sacos de dicho grano con destino a ciudades europeas como Londres, Liverpool, Hamburgo y Frankfurt. Todo lo cual incidió en un ostensible crecimiento de su patrimonio económico y en un aumento considerable de sus actividades comerciales. Con posterioridad y a lo largo de casi cuatro años, don Juan Rafael volvió a Chile en este tipo de viajes de negocios, arribando a dicho país en 1844, 1845, 1846 y 1848.

Se debe señalar también que durante 1845 Mora Porras inició un nuevo tipo de actividades comerciales cuando se asoció a varios ciudadanos acaudalados de nuestra patria para la conformación de una sociedad mercantil dedicada a la explotación de las minas del Monte del Aguacate. Asimismo, para 1849, don Juan Rafael expandió aún más sus horizontes financieros al convertirse en miembro de la sociedad comercial Gutiérrez y Cía., la cual se dedicaba al bodegaje, embalaje, embarque, desembarque y transporte de mercaderías desde y hacia el puerto de Puntarenas. Mismo año en que Mora entró a formar parte de la sociedad mercantil Mora-Simmons, cuyo objetivo principal fue la construcción de un canal fluvial entre las 
inmediaciones del río Barranca y el estero puntarenense para facilitar el transporte de productos comerciales.

\section{PRIMERA PRESIDENCIA}

Entre el 2 y el 9 de diciembre de 1849 se verificó el proceso electoral que determinó la primera llegada al solio presidencial de don Juan R. Mora Porras, quien obtuvo 49 votos de los 90 electores que sufragaron en dicha coyuntura. Período de gobierno que habiendo dado inicio el 30 de diciembre de 1849 y finalizado el 8 de mayo de 1853, le permitió al país beneficiarse en los más diversos campos de la ostensible experiencia comercial que Mora había acumulado desde hacía dos décadas y cuyas principales acciones gubernamentales en materia mercantil fueron las siguientes:

- 1850: Firma de un Tratado de Paz, Amistad y Comercio con la República de Guatemala (febrero); reglamentación de todos los aspectos concernientes a la materia hipotecaria (junio); firma de un Tratado de Paz, Amistad y Comercio con la República de Francia (julio); establecimiento de varias medidas para evitar los delitos de falsificación de monedas nacionales (agosto); desmonopolización del cultivo y comercio de Tabaco (septiembre); monopolización de la destilación de licores (septiembre); creación de la Aduana de Sarapiquí en la capital para regular el comercio de los productos llegados al país por esa vía fluvial (octubre); permiso para la comercialización de coñac y bebidas similares (diciembre); y prohibición de entrada al país de cualquier alambique u objeto similar que permitiese la destilación de licores (diciembre).

- 1851: Establecimiento de plazos determinados de tiempo para el otorgamiento de patentes comerciales (enero); creación de una Junta Itineraria en Guanacaste para el mejoramiento y cuido de los caminos de esa provincia (julio); supresión de la oficina de licores de San José y refundición en una nacional (julio); elaboración de una tabla de tasas, impuestos y demás derechos que debían cancelarse por productos importados del extranjero (agosto); supresión de todos los resguardos policiales de vigilancia de licores y creación de un resguardo central militar para ese propósito en San José (septiembre); e implementación del cargo de Inspector de Tesorerías y regulación de varios acápites relacionados a las rentas nacionales (octubre).

- 1852: Firma de un Tratado de Paz, Amistad y Comercio con la República de los EE.UU. (enero); esta- blecimiento de fábricas dedicadas a la producción comercial de cerveza (febrero); dictado de medidas destinadas a prevenir y evitar el contrabando de mercaderías (febrero); construcción de un faro en el puerto de Puntarenas para facilitar la navegación nocturna (marzo); reglamentación de la oficina de la Administración Principal (julio); disposición para sustituir el circulante de billetes antiguos por un grupo de billetes nuevos (septiembre); habilitación para que el puerto de Limón fuese utilizado como punto estratégico de comercio (octubre); firma de un Tratado de Paz, Amistad y Comercio con la República de Perú (noviembre); y firma de un Tratado de Paz, Amistad y Comercio con la República de los Países Bajos (noviembre).

- 1853 (enero-mayo): Concesión de una serie de derechos y amplitud de plazos para los individuos que se dedicaran al cultivo de cacao en las inmediaciones del camino a Sarapiquí y el valle de Matina (febrero); prohibición para la tala de cierto tipo de maderas en zonas reservadas (marzo); establecimiento de sanciones para los arrieros que no cumpliesen con los contratos comerciales que aceptasen (marzo); y prohibición para que una serie de víveres de manufactura o producción nacional fuesen sacados del país (abril).

\section{SEGUNDA PRESIDENCIA}

El 4 de abril de 1853 aconteció el proceso electoral que permitió la primera reelección de don Juan R. Mora P. como Presidente de la República, habiendo recibido 83 de los 91 votos electorales posibles. Así, su segundo mandato de gobierno comenzó el 8 de mayo de 1853 y concluyó el 8 de mayo de 1859, permitiendo la continuidad del exitoso derrotero comercial que Mora había iniciado cuatro años antes y en el que acontecieron las siguientes disposiciones comerciales y mercantiles:

- 1853 (mayo-diciembre): Creación de una Junta Itineraria en Cartago y otra en Puntarenas para el mejoramiento y cuido del camino entre ambos territorios (julio); establecimiento de una fábrica de ladrillos (octubre); emisión de un Reglamento de la Administración Principal de Rentas (noviembre); prohibición para que se navegase el río San Carlos como medida para evitar el contrabando realizado a través de esa vía fluvial (noviembre); disposición para que todos los individuos que fuesen dueños de una tienda o almacén comercial se inscribiesen en un registro para tal efecto (noviembre); y nombramiento de varios jueces especialistas en materia 
mercantil a lo interno de cada una de las provincias (diciembre).

- 1854: Reglamentación de los libros contables comerciales (enero); establecimiento de penas y sanciones para el delito de contrabando (febrero); regulación de los precios de las patentes para el comercio de licores extranjeros (abril); ampliación de las competencias jurisdiccionales de los jueces civiles para que pudiesen conocer sobre procesos de índole comercial (agosto); creación y reglamentación de la Oficina de la Contaduría Mayor (septiembre); reglamentación de la extracción de goma elástica (hule); establecimiento de una serie de parámetros judiciales para los procesos comerciales (octubre); y orden para amortizar con fondos nacionales a todos los documentos de crédito público (noviembre).

- 1855: Establecimiento de un registro de marcas y fierros vacunos en todas las provincias (mayo); reglamentación del registro de marcas y fierros vacunos provinciales (junio); decreto sobre el modo en que debían de cobrarse los derechos sobre la importación de licores extranjeros (julio); reglamentación sobre los procedimientos para la explotación de minas (octubre); y determinación de nuevas reglas para el comercio de licores extranjeros (octubre).

Entre el $1^{\circ}$ de marzo de 1856 y el $1^{\circ}$ de mayo de 1857 Costa Rica vivió la epopeya más trascendental y significativa de su historia, cuando se enfrentó al grupo mercenario multiétnico de La Falange Americana, conocido popularmente con el apelativo de filibusteros. Gloriosa coyuntura histórica que, bajo el nombre de Campaña Nacional 1856-1857, fue brillantemente dirigida por el Presidente Mora Porras y la cual, después de un intenso año y dos meses de belicosidad, le significó a nuestro territorio la reafirmación ostensible de su integridad territorial, de su soberanía y de su paz.

Casi de seguido al término de la guerra contra el grupúsculo filibustero, el Presidente Mora se dio a la imperiosa tarea de restablecer céleremente la normalidad del país, reanudando para ello, entre otros aspectos, asuntos concernientes a materia mercantil como:

- 1857 (mayo-diciembre): Establecimiento y reglamentación de dos oficinas de administración de licores (Puntarenas y Guanacaste) y una fábrica de destilación en Lepanto (mayo); liberalización del comercio de llantas de fierro (junio); implementación de una serie de multas para quienes comercializasen licores extranjeros sin contar con la patente respectiva (septiembre); Otorgamiento de licencias de exclusividad comercial para la apertura de una fábrica de loza vidriada, para una línea de diligencias entre San José y Cartago y una línea similar entre San José y Puntarenas (octubre); autorización para establecer en el país un sistema decimal (noviembre); y otorgamiento de licencias de exclusividad comercial para el establecimiento de una fábrica de fundición de hierro y para una empresa similar de fundición de bronce (noviembre).

- 1858: Concesión de una licencia de exclusividad comercial para la apertura de una línea de diligencias entre San José y Heredia (febrero); disposición para que los cuerpos policiales del país vigilasen que todos los productos hechos a base de harina se conservasen en buen estado al momento de venderse en establecimientos comerciales (junio); prevención para que toda mercadería llegada a Puntarenas fuese registrada en la aduana (junio); firma de un Tratado de Paz, Amistad y Comercio con la República de Bélgica (septiembre); Reglamentación de la administración de los fondos municipales de las provincias y nombramiento de un Juez de Hacienda Municipal (septiembre); y orden para que todas las pólizas liquidadas por los administradores de aduanas fuesen enviadas a la Contaduría Mayor para su verificación y aprobación (octubre).

- 1859 (enero-mayo): Autorización para la exportación de ciertos tipos de maderas autóctonas de la provincia de Guanacaste (enero); prohibición de la comercialización de cueros de venado con el fin de proteger a dicha especie animal (febrero); veda la tala y comercialización de cualquier tipo de árboles de la zona atlántica (marzo); y establecimiento de varias ordenanzas para la amortización de la deuda interior y el pago de los sueldos públicos (abril).

\section{TERCERA PRESIDENCIA}

La segunda reelección del Presidente Mora se dio entre el 3 y el 7 de abril de 1859, cuando obtuvo 87 de los 94 votos electorales en disputa. Hecho que le posibilitó no solo un tercer mandato de gobierno que principió el 8 de mayo de 1859, sino proseguir con la exitosa carrera de obras mercantiles y comerciales que había iniciado una década atrás, y entre las que pueden citarse: 


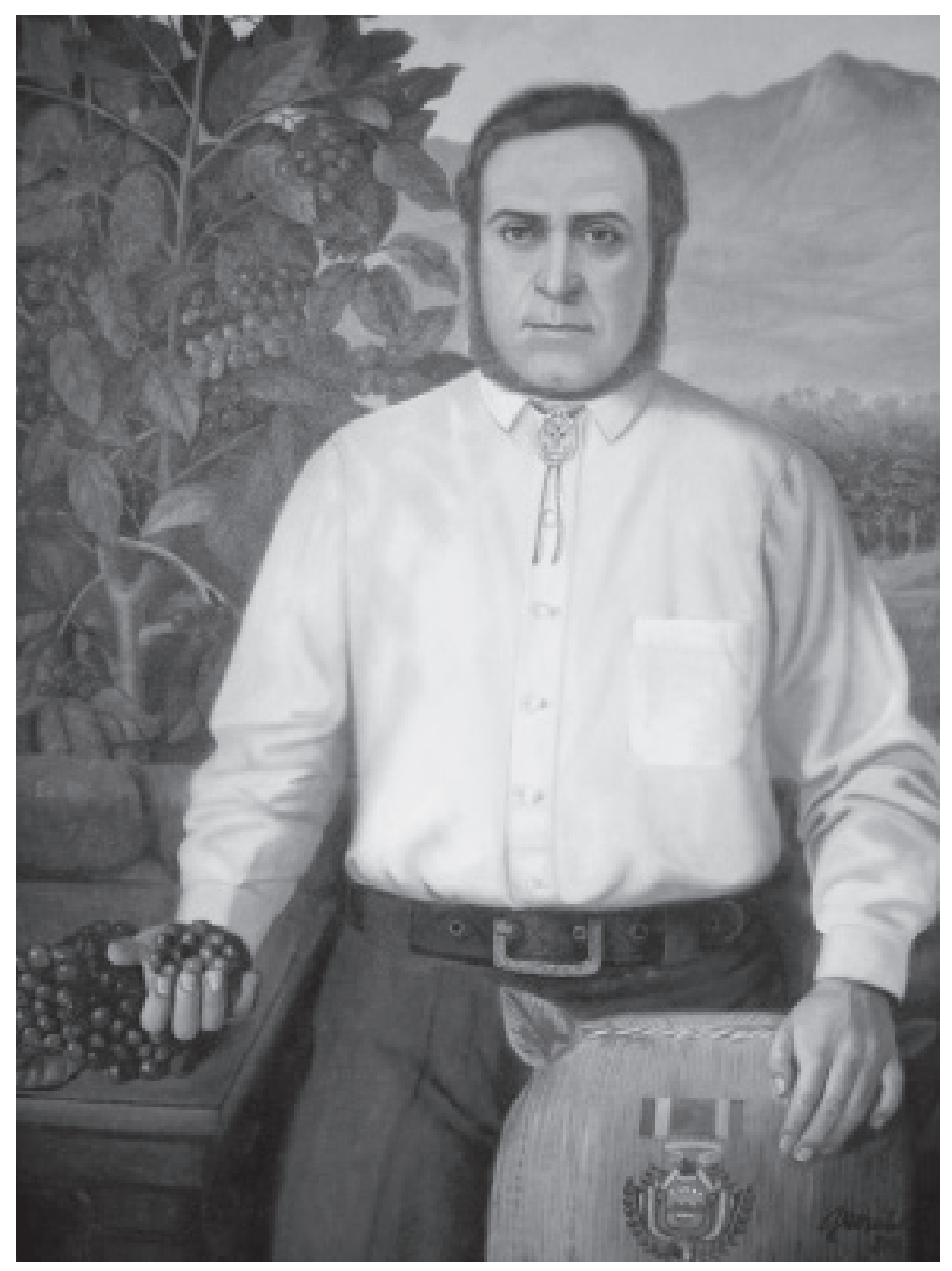

Juan Rafael Mora el emprendedor del siglo XIX Óleo por Gonzalo Morales, Colección Mauricio Ortiz Ortiz

1859 (mayo-agosto): Obligación de que todo abogado que pretendiese ejercer su profesión debía de contar con un capital mínimo de 3.000 pesos (julio); firma de una adenda al Tratado de Paz, Amistad y Comercio con la República de Francia (julio); y Establecimiento de un parámetro de aranceles por los servicios profesionales en Medicina (julio).

De modo lamentable, la tercera administración del Presidente Mora Porras fue abruptamente interrumpida en agosto de 1859 cuando un grupúsculo de antiguos enemigos suyos logró su defenestración al concatenar una serie de ilegítimos y oprobiosos afanes, entre los que, peculiarmente, sobresalieron una serie de intereses comerciales y financieros de ilegitima procedencia.

\section{TRES EPISODIOS MERCANTILES}

Dada la importancia y significación que revistieron, existen en el derrotero comercial desarrollado por don Juan R. Mora P. tres acontecimientos determinantes que marcaron de modo profuso tanto su vida privada como su ejercicio público: la conformación de la Sociedad Mora-Aguilar, la emisión del Código de Comercio y la fundación del Banco Nacional de Costa Rica. Grupo tripartito dentro del cual, tanto la citada sociedad mercantil como la entidad bancaria referida, serían los dos principales factores que incidirían en el golpe de Estado que se perpetró contra Mora en 1859.

a) La sociedad Mora-Aguilar: A partir del mes de octubre de 1842, don Juan R. Mora configuró una de las 
entidades mercantiles más afamadas de esa coyuntura, cuando se asoció al comerciante Vicente María Aguilar Cubero y ambos rubricaron la Ilamada Sociedad Mora-Aguilar, cuyo monto inicial de capital ascendió a la suma de 18.000 pesos. De seguido, se establecieron cuales serían las funciones a desempeñar por cada socio, correspondiéndole así a Aguilar el ejercicio de las actividades en Costa Rica (venta de las mercaderías, escritura de los libros de ingresos y egresos, pago de salarios, dirección del establecimiento, etc.), siendo que las acciones desplegadas en el extranjero serían realizadas por Mora (venta de productos nacionales en el extranjero, adquisición de bienes para la venta en Costa Rica, localización de fuentes de capital, búsqueda de nuevos mercados y negociación de nuevas contrataciones, etc.).

Ahora bien, transcurridos apenas seis años de la conformación de la Sociedad Mora-Aguilar, don Juan Rafael comenzó a darse cuenta de la evidente carestía de una serie de dineros y fondos pecuniarios en detrimento de su parte alícuota de patrimonio en dicha entidad mercantil. Razón la anterior por la que de inmediato disolvió su vínculo societario con Aguilar Cubero en febrero de 1848. Por ello mismo y sospechando tanto la existencia de algunas graves irregularidades contables de parte de su ex-socio, así como con la idea de contar con un acervo probatorio para un posible litigio, Mora Porras conservó los libros mercantiles y registrales de la fenecida Sociedad Mora-Aguilar.

Con posterioridad y para el amplio período de tiempo transcurrido entre 1849 y 1857 , el Presidente Mora decidió no entablar proceso judicial alguno en contra de Aguilar, dada la investidura presidencial que ejercía. Lo anterior a pesar de que durante esos años don Juan Rafael había logrado sustentar sus sospechas iniciales, pues, efectivamente, existió un sistemático y gravoso desfalco en su contra que según los cálculos contables realizados con base en los libros de la Sociedad Mora-Aguilar, ascendió a la ostensible suma de 350.000 pesos. Así las cosas, para 1857 y comprendiendo de modo paralelo que el plazo de prescripción para entablar un proceso judicial en contra de Aguilar estaba por fenecer, Mora decidió por fin actuar al respecto.

Fue en medio de esta coyuntura cuando Aguilar Cubero se enteró de la voluntad de Mora Porras para demandarlo, razón por la que le planteó la rúbrica de una transacción alterna que evitase llevar el litigio a sede judicial, lo cual fue aceptado por el mandatario. En ese sentido, dicha negociación implicó cinco estipulaciones: a) el reconocimiento expreso de Aguilar acerca de la deuda producida por la Sociedad Mora-Aguilar; b) el compromiso del ex-socio de don Juan Rafael para pagarle la suma de 100.000 pesos; c) la cancelación de la anterior suma por medio de cinco pagos sucesivos de $36.000,15.000,10.000,3.000$ y 36.000 pesos; d) la transferencia de 20.000 pesos más a favor de Mora, garantizada con dos propiedades inmuebles de Aguilar; y e) el cumplimiento de dichas condiciones con un plazo que terminaría en mayo de 1862. Así las cosas, todo el panorama anterior explica porque Aguilar Cubero no podia presentar reclamaciones, como afirma Argüello Mora (1860):

No podía, bajo ninguna circunstancia, estar satisfecho por las reclamaciones presentadas por Mora...por eso, empezó a maquinar su venganza, cuyo proyecto fundamental consistía en la caída política de Mora. Por ello su deseo y efectiva colaboración en la realización del golpe del 14 de agosto.

(Mora) tuvo la desgracia de asociarse en su juventud con un negociante que después llegó a ser el ciudadano más rico de le República, el señor Vicente Aguilar, cuya gestión poco leal le produjo una pérdida cercana a 1.500.000 francos. Convicto de infidelidad y bajo la amenaza de un juicio que le haría perder la reputación, el señor Aguilar hubo de transigir y el señor Mora obtuvo el compromiso de recibir escalonadamente medio millón. Pero también se ganó el enemigo más irreconciliable. El señor Aguilar se interesó en adelante no solo en arruinar a su acreedor sino también en su muerte...su gran fortuna le otorgó una influencia determinante. Sería necesario conocer bien poco la naturaleza humana y sobre todo la avidez implacable de los hombres de dinero, para no percibir la preponderancia de su rol en la revolución...todo el mundo conocía el detalle de las sustracciones comerciales del señor Aguilar...Esta página de sangre (el asesinato de Mora) no fue más que un ajuste de cuentas. El señor Aguilar agregó la confiscación y se mostró dispuesto a cebarse contra la familia y los seguidores de su antiguo socio.

b) El Código de Comercio: La primera legislación mercantil que tuvo vigencia en Costa Rica fue emitida en 1737, bajo el reinado del rey Felipe V, con el nombre de Ordenanzas de la ilustre Universidad y Casa de Contratación de la muy noble y muy leal villa de Bilbao, las cuales regularían dicha actividad hasta mediados del 
siglo XIX. Así, en virtud de esta ley española, se fundó en 1793 un Consulado de Comercio (tribunal) en la antigua Capitanía General de Guatemala a la que nuestro territorio pertenecía. Mismo año en el que se nombró un Diputado Consular (juez) en la ciudad de Cartago para dirimir, en primera instancia, los litigios mercantiles que acontecieran en suelo costarricense.

A partir de 1821 las actividades comerciales continuaron bajo la égida de las Ordenanzas de Bilbao, hasta que dicha circunstancia feneció en 1841 al promulgarse el afamado Código General del Estado de Costa Rica, cuya sección dedicada al Derecho Civil comenzó a implementarse como mecanismo legal para discernir los conflictos mercantiles. Pero, tanto la práctica rutinaria del comercio, así como la propia naturaleza jurídica de la mayoría de las figuras atinentes a esa materia, rápidamente hicieron palpable la evidente carestía del Derecho Civil como mecanismo regulador del comercio, propiciando entonces la necesidad de contar con un ordenamiento legal propio.

Fue en medio de esta coyuntura cuando el Presidente Mora Porras decidió dotar a Costa Rica de su primera legislación codificada en materia mercantil, dado el enorme auge que dicha actividad había alcanzado en nuestra patria. Para ello y con la idea de contar con una base jurídica de sólido y reconocido prestigio, se implementó el estudio, revisión y análisis de dos leyes mercantiles españolas emitidas en 1830: el Código de Comercio Español y el Código de Enjuiciamiento en Materias Comerciales. Después de varias sesiones legislativas de propuestas y deliberaciones, ambas legislaciones hispanas fueron modificadas y adicionadas en varios de sus acápites con el fin de adaptarlas a los bemoles del ordenamiento jurídico costarricense.

Así las cosas, el 6 de junio de 1853 le correspondió al Presidente Mora rubricar la emisión de nuestro primer Código de Comercio (constituido por cinco libros temáticos: I) De los Comerciantes y Agentes de Comercio; II) De los contratos del Comercio en general, sus formas y efectos; III) Del Comercio Marítimo; IV) De las Quiebras; y V) De la administración de justicia en los negocios de Comercio, distribuidos en 1169 artículos, así como firmar la pionera Ley de Enjuiciamiento en Negocios y Causas de Comercio. El primero de las cuales entró en vigencia en enero de 1854, mientras que la segunda comenzó a regir desde el propio mes de junio de 1853.

Con posterioridad, la Ley de Enjuiciamiento en Negocios y Causas de Comercio fue derogada en 1859, disponiéndose que todo proceso mercantil volviese a regirse por lo dispuesto en el Código General del Estado de Costa Rica de 1841, es decir, bajo los parámetros establecidos por el Derecho Civil. Hasta que casi treinta años después y como consecuencia de la entrada en vigencia del Código de Procedimientos Civiles de 1888, la materia de juzgamiento mercantil empezó a regularse bajo las normas del Derecho Procesal Civil, manteniéndose incólume esta disposición en el Código de Procedimientos Civiles de 1933 y en el actual Código Procesal Civil de 1990. Mientras que en lo atinente a la vigencia normativa del Código de Comercio, ésta se mantuvo por el prolongado espacio de ciento diez años, cuando fue derogado por el actual Código de Comercio emitido en 1964.

c) El Banco Nacional de Costa Rica: El término de la Campaña Nacional supuso, entre otros aspectos, una reducción considerable del erario público, pues dicho rubro se había utilizado para financiar todos los acápites concernientes a dicha guerra. Asimismo, dicha confrontación provocó un grave deterioro en el patrimonio de muchos de los costarricenses que acudieron al Ilamado patriótico en defensa de nuestra soberanía, pues, desde marzo de 1856, gran cantidad de fincas y propiedades de cultivo habían quedado sin utilizarse por la guerra, por lo que la producción económica de nuestra nación se encontraba en franco deterioro.

Fue entonces cuando, ante el panorama descrito, el Presidente Mora concibió la idea de fundar en Costa Rica una entidad bancaria pública que permitiese el fortalecimiento y reestructuración de las arcas pecuniarias de nuestro país y, lo más importante, sirviese de plataforma idónea para el financiamiento crediticio accesible de pequeños y medianos agricultores, campesinos, productores y demás similares, para que desarrollasen sus respectivos negocios.

Así las cosas, en el mes de junio de 1857, el gobierno suscribió un contrato con el empresario argentino Crisanto Medina Blanco por medio del cual se fundó el pionero Banco Nacional de Costa Rica, cuyo patrimonio inicial tripartito se compuso de capital privado costarricense, dinero particular europeo y fondos de naturaleza pública, y cuya apertura se dio en junio de 1858.

De modo lamentable, la novel entidad bancaria no logró consolidarse y tuvo que cerrar en marzo de 1859, debido a que, por una parte, aconteció la imposibilidad del principal accionista extranjero del banco, el ciudadano inglés John Carmichael, para aportar la suma 
inicial de 30.000 pesos a que se había comprometido, en razón de un repentino estado de quiebra financiera. Mientras que, por otra parte, y como principal razón de fondo, como menciona Bernardo Villalobos (1981):

La oposición de algunos comerciantes miembros de la oligarquía y del sector agroexportador (costarricenses) con fuertes vínculos financieros con la banca británica...debido a que controlaban el crédito usurero a través de las casas consignatarias...pues la idea de crear un banco emisor con participación estatal era inadmisible...(pues)el Estado no debía tener ninguna participación en el negocio bancario (ya que se ponía) en peligro el lucrativo negocio del préstamo privado usurero a los pequeños cafetaleros proporcionado por la oligarquía y los comerciantes agroexportadores.

A pesar de lo anterior y siempre con el objetivo de dotar de una fuente crediticia no agiotista, ni leonina, al sector productivo costarricense de escasos recursos, el Presidente Mora rubricó un segundo contrato con el empresario Medina Blanco para la reapertura del Banco Nacional de Costa Rica. Negociación que se firmó el 4 de agosto de 1859 y que, como puede colegirse, fue la causa directa para que tan solo diez días más tarde, don Juan Rafael fuese víctima del golpe de Estado acontecido en la madrugada del 14 de agosto de ese mismo año, ya que el trasfondo del golpe de estado de agosto de 1859, fue la existencia del Banco Nacional de Costa Rica según Carmen Gómez (1986):

Si el banco hubiera funcionado, los cafetaleros que tenían en sus manos el negocio de prestar dinero al pequeño y mediano agricultor, hubiera terminado, de ahí que promovieran la caía del Presidente Mora...Estos primeros esfuerzos por parte del gobierno por crear instituciones bancarias... tenían que producir reacciones negativas de parte de los círculos financieros que habían venido manejando el crédito particular.

Así las cosas, el exitoso derrotero comercial y mercantil que don Juan Rafael Mora Porras desarrolló a lo largo de toda su vida privada, fue también el que logró desempeñar con brillante impronta a favor de Costa Rica durante sus tres mandatos presidenciales, aunque, lamentablemente, fuese también ese mismo éxito el que produjese el encono y rencor de algunos pocos adversarios. Todo lo cual lo convirtió en el paradigma del empresario por antonomasia del siglo decimonónico.

\section{REFERENCIAS BIBLIOGRÁFICAS}

\section{Fuentes primarias (Documentos del Archivo Nacional)}

Del fondo Congreso:

Expedientes No. 5097, 5158, 5233， 5310, 5934, 7018, 7321, 7483, 7873, 17879, 17902.

Del fondo Guerra y Marina:

Expedientes No. 4559, 4776, 4782, 5503, 7924, 8160, 8172, 8858, 8860, 8865, 8867, 8873, 8879.

Del fondo Relaciones Exteriores:

Expedientes No. 1701

Del fondo Protocolos de San José:

Expedientes núm. 44 (1827) y Microfilm 44469F (1832), 55 (1834)

\section{Fuentes secundarias}

Academia de Geografía e Historia de Costa Rica. (1981). Mensajes Presidenciales: años 1824-1858 (tomo I). San José: Editorial Texto Ltda

Archivo Nacional. (1961). Causa seguida contra don Francisco M. Iglesias por calumnia a S. E. el señor Presidente de la República. Revista de los Archivos Nacionales, núms. 7-12.

Archivo Nacional. (1961). Conjuración de Iglesias y Tinoco, Revista de los Archivos Nacionales, núms 7-12.

Argüello Mora, M. (1860). Cuestión Mora y Aguilar: exposición de uno de los hechos que motivaron los sucesos del 14 de agosto (Juan R. Mora). El Salvador: Imprenta A. Liévano.

Argüello Mora, M. (1861). Cuestión Mora y Aguilar (réplica). El Salvador: Imprenta A, Liévano.

Argüello Mora, M. (1942). Cuestión Mora y Aguilar. Revista de los Archivos Nacionales, núms. 3-4.

Argüello Mora, M. (2007). Obras literarias e históricas. San José: Editorial Costa Rica.

Brenes Córdoba, A. (1913). Historia del Derecho. San José: Tipografía Lehmann.

Castañeda, F. (1915). Juan Rafael Mora: primer centenario de su nacimiento. En: Castro Saborío, O. (1915). El centenario del Benemérito de la Patria ex-Presidente de la República y General don Juan Rafael Mora Porras. San José: Tipografía Nacional.

Chacón Méndez, E. (2002). Índice cronológico de la Campaña Nacional 1856-1857. Museo histórico cultural Juan Santamaría. Alajuela, Costa Rica. 
Don Juan Rafael Mora: Empresario por antonomasia del siglo decimonónico

Corrales J. (2000). El Banco Anglo Costarricense y el desarrollo económico de Costa Rica (1863-1914). Editorial Costa Rica: San José.

Durán Luzio, J. (2011). Juan Rafael Mora Porras: escritos selectos (primer ensayista costarricense). San José: Imprenta Lara y Segura.

Fallas Santana, C. (2004). Élite, negocios y política en Costa Rica (1849-1859). Museo histórico cultural Juan Santamaría. Alajuela, Costa Rica.

Fernández Guardia, R. (1984). Cartilla histórica de Costa Rica. San José: Litografía Lehmann S.A.

Fournier Acuña, F. (1978). Historia del Derecho. San José: Ediciones Juricentro S.A.

Gobierno de Costa Rica. Colección de Leyes y Decretos (1849, 1850, 1851, 1852, 1853, 1854, 1855, 1856, 1857, 1858, 1859-1860). San José: Imprenta de la Paz.

Gobierno de Costa Rica. (1860). Exposición de los motivos del cambio político acaecido el 14 de agosto de 1859. San José: Imprenta Nacional.

Gobierno de Costa Rica. (1861). Exposición histórica de la revolución del 15 de septiembre de 1860 acompañada de algunas reflexiones sobre la situación del país antes y después del 14 de agosto de 1859. San José: Imprenta del Gobierno

González Víquez, C. (1978). El sufragio en Costa Rica ante la historia y la legislación. San José: Editorial Costa Rica.

Gómez. C. (1986). Las Instituciones Costarricenses del siglo XIX. San José: Editorial Costa Rica.

Guier Esquivel, Jorge E. (1968). Historia del Derecho (tomo II). San José: Editorial Costa Rica.

Iglesias Llorente, F. M. (1856).Vindicación de Francisco María Iglesias. San José: Imprenta de la Paz.

Iglesias Llorente, F. M. (1961). Consejo de Guerra. Revista de los Archivos Nacionales, núms. 7-12.

Jiménez Blanco, S. (1874). Elementos de Derecho Civil y Penal de Costa Rica. San José: Imprenta de Guillermo Molina.
Jiménez Mora, E., Jiménez Mora, M. y Loría Mora, C. (1942). Carta sobre la cuestión Mora y Aguilar. Revista de los Archivos Nacionales, núms. 7-8.

Jinesta Muñoz, C. (1962) El fusilamiento de don Juan Rafael Mora. En: (1962). Paginas Ticas. San José: Librería Las Américas.

Jinesta Muñoz, C. (1929). Juan Rafael Mora. San José: Imprenta Alsina.

León Sáenz, J. (2002). Evolución del comercio exterior y del trasporte marítimo de Costa Rica (1821-1900). San José: Editorial de la Universidad de Costa Rica.

Meléndez Chaverri, C. (1978). Documentos fundamentales del siglo XIX. San José: Editorial Costa Rica.

Obando Cairol, E. (2010). Mora y Cañas en familia. Revista Comunicación (19), núm. especial, 28-43.

Obregón Loría, R. (1981). Hechos militares y políticos. Museo Histórico Cultural Juan Santamaría. Alajuela, Costa Rica.

Obregón Quesada, C. (2000). El proceso electoral y el Poder Ejecutivo en Costa Rica (1808-1998). San José: Editorial Universidad de Costa Rica.

Rodríguez Porras, A. (1955). Juan Rafael Mora Porras y la guerra contra los Filibusteros. San José: Imprenta Las Américas.

Rodríguez, E. (2014). Campaña Nacional, crisis económica y capitalismo: Costa Rica en la época de Juan Rafael Mora (1850-1860). San José: Editorial Costa Rica.

Sáenz Carbonell, J. (1996). Historia diplomática de Costa Rica (1821-1910). San José: Editorial Juricentro.

Sáenz Carbonell, J. (2008). Los sistemas normativos en la historia de Costa Rica. Heredia: Ediciones Chico.

Soley Güell, T. (1975). Compendio de historia económica y hacendaria de Costa Rica. San José: Editorial Costa Rica.

Streber, F. (1942). Vindicación de D. Vicente Aguilar. Revista de los Archivos Nacionales, núms. 5-6.

Villalobos B. (1981). Bancos emisores y bancos hipotecarios en Costa Rica (1850-1910). San José: Editorial Costa Rica. 